\title{
The effect of maternal and child health and family planning services on mortality: Is prevention enough?
}

\author{
Vincent Fauveau, Bogdan Wojtyniak, Jyotsnamoy Chakraborty, Abdul Majid Sarder, \\ André Briend
}

\begin{abstract}
Objective-To examine the impact on mortality of a child survival strategy, mostly based on preventive interventions.

Design-Cross sectional comparison of cause specific mortality in two communities differing in the type, coverage, and quality of maternal and child health and family planning services. In the intervention area the services were mainly preventive, community based, and home delivered.
\end{abstract}

Subjects-Neonates, infants, children, and mothers in two contiguous areas of rural Bangladesh.

Interventions - In the intervention area community health workers provided advice on contraception and on feeding and weaning babies; distributed oral rehydration solution, vitamin $A$ tablets for children under 5 , and ferrous fumarate and folic acid during pregnancy; immunised children; trained birth attendants in safe delivery and when to refer; treated minor ailments; and referred seriously ill people and malnourished children to a central clinic.

Main outcome measures-Overall and age and cause specific death rates, obtained by a multiple step "verbal autopsy" process.

Results-During the two years covered by the study overall mortality was $17 \%$ lower among neonates, $9 \%$ lower among infants aged 1-5 months, 30\% lower among children aged 6-35 months, and 19\% lower among women living in the study area than in those living in the control area. These differences were mainly due to fewer deaths from neonatal tetanus, measles, persistent diarrhoea with severe malnutrition among children, and fewer abortions among women.

Conclusions-The programme was effective in preventing some deaths. In addition to preventive components such as tetanus and measles immunisation, health and nutrition education, and family planning, curative services are needed to reduce mortality further. \section{Disease}

Vincent physician

Bogdan Wojtyniak, PHD, demographer

Jyotsnamoy Chakraborty, manager, health services

Abdul Majid Sarder, manager, demographic surveillance system

André Briend, $\mathrm{MD}$, nutritionist

Correspondence and requests for reprints to: $\mathrm{Dr} \mathrm{V}$ Fauveau, ICDDR,B, GPO Box 128, Dhaka 1000,

Bangladesh. sample populations were too small, the death were too low, there was no control population, or thęre was no precise assessment of the cause of death. ${ }^{5}$ Matlab, the field station of the International Centre for Diarrhoeal Disease Research, Bangladesh, is well equipped to overcome these problems. It has a population of 196000 under demographic surveillance, it includes a control area, and the causes of death are carefully documented. In this study cause specific death rates among infants, children, and women in two neighbouring areas receiving different levels of services were compared and evaluated to help to define priorities for future service development.

\section{Subjects and methods}

Matlab lies in the Ganges delta, $45 \mathrm{~km}$ south east of Dhaka, the capital of Bangladesh. Most people live by subsistence farming and travel by waterways. In 1986 the area had a population density of 700 per $\mathrm{km}^{2}$, an adult literacy rate of $30 \%$, a total fertility rate of 6 per woman, and an infant mortality of 95/1000 live births. Fewer than $5 \%$ of the children who died in the whole study area during 1986-7 had sought care from a hospital.

The research centre has operated a diarrhoea treatment centre in the middle of the study area since 1963 and demographic surveillance since 1966: every household is visited twice a month by one of 110 female community health workers, who record births, deaths, migrations and marriages. ${ }^{8}$

In 1978 a maternal and child health and family planning services programme was introduced in half of the area. ${ }^{9}$ Most of the services were preventive and delivered at home by the community health workers. They were implemented gradually and included: $(a)$ a wide range of contraceptive methods, accompanied by measures to encourage motivation and take care of side effects; this service resulted in a contraceptive use rate among married couples of $48 \%$ in $1986-7 ;(b)$ an oral rehydration therapy programme, including the placement of stocks of oral rehydration solution packets in every cluster of households, resulting in a $90 \%$ coverage rate; $(c)$ an immunisation programme, resulting in coverage rates of $82 \%$ for measles, $58 \%$ for three doses of diphtheriatetanus-pertussis-polio, and $88 \%$ for two doses of tetanus toxoid among married women in 1986-7; $(d)$ distribution of ferrous fumarate and folic acid tablets during the last four months of pregnancy; $(e)$ training of traditional birth attendants to use safe delivery kits and to refer complicated deliveries; $(f)$ nutritional advice about using colostrum, early introduction of energy rich weaning foods, the need for green leafy vegetables, and the need to breast feed beyond the age of 6 months, particularly during illnesses; $(g)$ treatment of minor ailments such as helminthiasis and skin problems by female paramedics in four decentralised maternal and child health clinics; $(h)$ six monthly distribution of vita$\min A$ capsules to children aged under 5 ( $96 \%$ coverage); and $(i)$ referral of severely ill people and malnourished children to a central clinic staffed by two women doctors with a 10 bed nutrition rehabilitation unit. 
In the other half of the area, the comparison area, the population was served by understaffed government clinics, lacking in supplies and supervision, and grossly underused. Fewer than $3 \%$ of the children and mothers were immunised, fewer than $20 \%$ of couples used contraceptives, and referral to health centres was minimal. Coverage for oral rehydration solution packets and vitamin $\mathrm{A}$, however, was comparable to that in the study area because these were distributed by the same community health workers, and people were offered the same referral facilities as in the study area for diarrhoea treatment and nutritional rehabilitation at the Matlab hospital.

This study reports the deaths of children aged under 3 years and women aged 15-44, which occurred in both areas from January 1986 to December 1987. The cause of death was assessed by a multiple step procedure known as "verbal autopsy." Deaths were detected by community health workers during their biweekly home visits. A health assistant interviewed the family within six weeks to collect sociodemographic information and record the symptoms preceding death. This history, collected in a semistructured mode, was written in the local language, preserving local idioms. The information was reviewed independently by three doctors, who assigned the most likely primary and underlying causes of death. The final cause was then assessed on a majority rule and coded according to a classification derived from the World Health Organisation's recommended classification. ${ }^{10}$ In case of complete disagreement additional information requested by the doctors was collected. Additional structured questionnaires were taken by a specially trained female interviewer to the houses where neonates or women had died to investigate better some difficult histories such as neonatal disorders, obstetric problems, abortion, or violence.

In some cases it was not possible to use the death categories recommended by the World Health Organisation. No causal information on diarrhoeal diseases was available, so they were classified according to the clinical type of diarrhoea: acute watery, acute non-watery (combining bloody and mucoid diarrhoea), persistent, and persistent with severe malnutrition.

Given that the total population under 5 years was around 30000 , it was impossible to get an objective measure of the degree of malnutrition before death. ${ }^{11}$ Hence the diagnosis of severe malnutrition was applied when parents or relatives of the dead child had noted a rapid or recent wastage of the child's tissues before death or the recent appearance of tibial oedema. In a subsample of 253 cases in which the mid upper arm circumference had been measured within a month of death the degree of agreement between the assessment

TABLE I-Cause of death among neonates (<31 days) in study and comparison areas of Matlab 1986-7 (rates per 1000 live births)

\begin{tabular}{|c|c|c|c|c|c|c|c|}
\hline \multirow[b]{2}{*}{ Cause of death } & \multicolumn{3}{|c|}{ Study area (6663 live births) } & \multicolumn{3}{|c|}{ Comparison area ( 7677 live births) } & \multirow{2}{*}{$\begin{array}{l}\text { Difference } \\
\text { between } \\
\text { rates }\end{array}$} \\
\hline & No & Rate & $\%$ & No & Rate & $\%$ & \\
\hline Complications of small size at birth & 132 & $19 \cdot 8$ & $44 \cdot 1$ & 144 & $18 \cdot 8$ & $34 \cdot 8$ & $1 \cdot 0$ \\
\hline Birth trauma & 43 & $6 \cdot 5$ & $14 \cdot 4$ & 44 & $5 \cdot 7$ & $10 \cdot 6$ & 0.8 \\
\hline Neonatal tetanus & 20 & $3 \cdot 0$ & 6.7 & 85 & $11 \cdot 1$ & $20 \cdot 5$ & $-8 \cdot 1^{\star \star \star}$ \\
\hline Neonatal pneumonia & 30 & 4.5 & $10 \cdot 0$ & 42 & $5 \cdot 5$ & $10 \cdot 1$ & $-1 \cdot 0$ \\
\hline Acute watery diarrhoea & 1 & $0 \cdot 2$ & $0 \cdot 3$ & 3 & $0 \cdot 4$ & 0.7 & -0.2 \\
\hline Acute non-watery diarrhoea & 0 & $0 \cdot 0$ & 0.0 & 3 & $0 \cdot 4$ & $0 \cdot 7$ & -0.4 \\
\hline Persistent diarrhoea & 1 & $0 \cdot 2$ & 0.3 & 0 & 0.0 & $0 \cdot 0$ & 0.2 \\
\hline Other neonatal infections & 32 & $4 \cdot 8$ & $10 \cdot 7$ & 36 & $4 \cdot 7$ & $8 \cdot 7$ & $0 \cdot 1$ \\
\hline Other neonatal disorders & 7 & $1 \cdot 1$ & $2 \cdot 3$ & 9 & $1 \cdot 2$ & $2 \cdot 2$ & $-0 \cdot 1$ \\
\hline Impossible to specify & 33 & $5 \cdot 0$ & $11 \cdot 0$ & 48 & $6 \cdot 3$ & $11 \cdot 6$ & $-1 \cdot 3$ \\
\hline All causes & 299 & $44 \cdot 9$ & $100 \cdot 0$ & 414 & 53.9 & $100 \cdot 0$ & $-9 \cdot 0^{\star}$ \\
\hline
\end{tabular}

${ }^{\star} \mathrm{p}<0 \cdot 05 ; \star \star \star \mathrm{p}<0 \cdot 001$. Some totals do not add up because of rounding.

TABLE II-Cause of death among infants aged 1-5 months in study and comparison areas of Matlab 1986-7 (rates per 1000 live births)

\begin{tabular}{|c|c|c|c|c|c|c|c|}
\hline \multirow[b]{2}{*}{ Cause of death } & \multicolumn{3}{|c|}{ Study area $(6663)$} & \multicolumn{3}{|c|}{ Comparison area $(7677)$} & \multirow{2}{*}{$\begin{array}{c}\text { Difference } \\
\text { between } \\
\text { rates }\end{array}$} \\
\hline & No & Rate & $\%$ & No & Rate & $\%$ & \\
\hline Acute watery diarrhoea & 13 & 2.0 & $7 \cdot 8$ & 25 & $3 \cdot 3$ & $11 \cdot 7$ & $-1 \cdot 3$ \\
\hline Acute non-watery diarrhoea & 5 & 0.8 & $3 \cdot 0$ & 11 & $1 \cdot 4$ & $5 \cdot 2$ & -0.6 \\
\hline Persistent diarrhoea & 9 & $1 \cdot 4$ & $5 \cdot 4$ & 3 & $0 \cdot 4$ & $1 \cdot 4$ & $1 \cdot 0$ \\
\hline Persistent diarrhoea with severe malnutrition & 4 & $0 \cdot 6$ & $2 \cdot 4$ & 11 & $1 \cdot 4$ & $5 \cdot 2$ & $-0 \cdot 8$ \\
\hline Total diarrhoeal diseases & 31 & $4 \cdot 7$ & $18 \cdot 6$ & 50 & $6 \cdot 5$ & $23 \cdot 5$ & $-1 \cdot 8$ \\
\hline Acute lower respiratory infection & 54 & $8 \cdot 1$ & $32 \cdot 3$ & 77 & $10 \cdot 0$ & $36 \cdot 2$ & -1.9 \\
\hline Acute lower respiratory infection with severe malnutrition & 9 & 1.4 & $5 \cdot 4$ & 6 & 0.8 & 2.8 & 0.6 \\
\hline Whooping cough & 2 & $0 \cdot 3$ & $1 \cdot 2$ & 3 & $0 \cdot 4$ & $1 \cdot 4$ & $-0 \cdot 1$ \\
\hline Total acute respiratory infection & 65 & $9 \cdot 8$ & $38 \cdot 9$ & 86 & $11 \cdot 2$ & $40 \cdot 4$ & $-1 \cdot 4$ \\
\hline Skin and subcutaneous infection & 1 & $0 \cdot 2$ & $0 \cdot 6$ & 2 & $0 \cdot 3$ & 0.9 & $-0 \cdot 1$ \\
\hline Fever of unknown origin & 6 & $0 \cdot 9$ & $3 \cdot 6$ & 7 & 0.9 & $3 \cdot 3$ & 0.0 \\
\hline Other infectious diseases & 7 & $1 \cdot 1$ & $4 \cdot 2$ & 12 & $1 \cdot 6$ & $5 \cdot 6$ & -0.5 \\
\hline Total other infectious diseases & 14 & $2 \cdot 1$ & $8 \cdot 4$ & 21 & $2 \cdot 7$ & $9 \cdot 9$ & $-0 \cdot 6$ \\
\hline Other severe malnutrition & 22 & $3 \cdot 3$ & $13 \cdot 2$ & 21 & $2 \cdot 7$ & $9 \cdot 9$ & $0 \cdot 6$ \\
\hline Drowning & 1 & $0 \cdot 2$ & 0.6 & 0 & $0 \cdot 0$ & $0 \cdot 0$ & $0 \cdot 2$ \\
\hline Other accidents & 13 & $2 \cdot 0$ & $7 \cdot 8$ & 7 & 0.9 & $3 \cdot 3$ & $1 \cdot 1$ \\
\hline Total injuries, accidents & 14 & $2 \cdot 1$ & $8 \cdot 4$ & 7 & $0 \cdot 9$ & $3 \cdot 3$ & $1 \cdot 2$ \\
\hline Other causes & 5 & $0 \cdot 8$ & $3 \cdot 0$ & 4 & 0.5 & 1.9 & $0 \cdot 3$ \\
\hline Impossible to specify & 16 & $2 \cdot 4$ & $9 \cdot 6$ & 24 & $3 \cdot 1$ & $11 \cdot 3$ & $-0 \cdot 7$ \\
\hline All causes & 167 & $25 \cdot 1$ & $100 \cdot 0$ & 213 & $27 \cdot 7$ & $100 \cdot 0$ & $-2 \cdot 6$ \\
\hline
\end{tabular}

Some totals do not add up because of rounding. 


\begin{tabular}{|c|c|c|c|c|c|c|c|}
\hline \multirow[b]{2}{*}{ Cause of death } & \multicolumn{3}{|c|}{ Study area $(n=14551)$} & \multicolumn{3}{|c|}{ Comparison area $(n=16276)$} & \multirow{2}{*}{$\begin{array}{c}\text { Difference } \\
\text { between } \\
\text { rates }\end{array}$} \\
\hline & No & Rate & $\%$ & No & Rate & $\%$ & \\
\hline Acute watery diarrhoea & 22 & 1.5 & $8 \cdot 8$ & 23 & $1 \cdot 4$ & $5 \cdot 6$ & $0 \cdot 1$ \\
\hline Acute non-watery diarrhoea & 29 & $2 \cdot 0$ & $11 \cdot 6$ & 32 & $2 \cdot 0$ & $7 \cdot 8$ & $0 \cdot 0$ \\
\hline Post measles diarrhoea & 2 & $0 \cdot 1$ & $0 \cdot 8$ & 34 & $2 \cdot 1$ & $8 \cdot 3$ & $-2 \cdot 0 \star \star \star$ \\
\hline Persistent diarrhoea & 21 & $1 \cdot 4$ & $8 \cdot 4$ & 25 & 1.5 & $6 \cdot 1$ & $-0 \cdot 1$ \\
\hline Persistent diarrhoea with severe malnutrition & 56 & $3 \cdot 8$ & $22 \cdot 4$ & 108 & $6 \cdot 6$ & $26 \cdot 2$ & $-2 \cdot 8^{\star \star \star}$ \\
\hline Total diarrhoeal diseases & 130 & $8 \cdot 9$ & $52 \cdot 0$ & 222 & $13 \cdot 6$ & $53 \cdot 9$ & $-4 \cdot 7 \star \star \star$ \\
\hline Acute lower respiratory infection & 25 & $1 \cdot 7$ & $10 \cdot 0$ & 48 & 2.9 & $11 \cdot 7$ & $-1 \cdot 2^{\star}$ \\
\hline Acute lower respiratory infection with severe malnutrition & 3 & $0 \cdot 2$ & $1 \cdot 2$ & 9 & 0.6 & $2 \cdot 2$ & $-0 \cdot 4$ \\
\hline Post measles pneumonia & 1 & $0 \cdot 1$ & $0 \cdot 4$ & 10 & $0 \cdot 6$ & $2 \cdot 4$ & $-0 \cdot 5^{\star}$ \\
\hline Whooping cough & 2 & $0 \cdot 1$ & $0 \cdot 8$ & 6 & $0 \cdot 4$ & 1.5 & $-0 \cdot 3$ \\
\hline Total acute respiratory infection & 31 & $2 \cdot 1$ & $12 \cdot 4$ & 73 & $4 \cdot 5$ & $17 \cdot 7$ & $-2 \cdot 4^{\star \star \star}$ \\
\hline Measles & 0 & $0 \cdot 0$ & $0 \cdot 0$ & 3 & $0 \cdot 2$ & $0 \cdot 7$ & $-0 \cdot 2$ \\
\hline Tetanus & 1 & $0 \cdot 1$ & $0 \cdot 4$ & 3 & $0 \cdot 2$ & $0 \cdot 7$ & $-0 \cdot 1$ \\
\hline Skin and subcutaneous infection & 2 & $0 \cdot 1$ & $0 \cdot 8$ & 3 & $0 \cdot 2$ & $0 \cdot 7$ & $-0 \cdot 1$ \\
\hline Fever of unknown origin & 6 & $0 \cdot 4$ & $2 \cdot 4$ & 11 & $0 \cdot 7$ & $2 \cdot 7$ & $-0 \cdot 3$ \\
\hline Other infectious diseases & 3 & $0 \cdot 2$ & $1 \cdot 2$ & 5 & $0 \cdot 3$ & $1 \cdot 2$ & $-0 \cdot 1$ \\
\hline Total other infectious diseases & 12 & $0 \cdot 8$ & $4 \cdot 8$ & 25 & $1 \cdot 5$ & $6 \cdot 1$ & $-0 \cdot 7$ \\
\hline Other severe malnutrition & 17 & $1 \cdot 2$ & $6 \cdot 8$ & 20 & $1 \cdot 2$ & $4 \cdot 9$ & -0.0 \\
\hline Drowning & 40 & $2 \cdot 7$ & $16 \cdot 0$ & 38 & $2 \cdot 3$ & $9 \cdot 2$ & $0 \cdot 4$ \\
\hline Extended burns & 2 & $0 \cdot 1$ & $0 \cdot 8$ & 3 & $0 \cdot 2$ & $0 \cdot 7$ & $0 \cdot 1$ \\
\hline Other accidents & 3 & $0 \cdot 2$ & $1 \cdot 2$ & 2 & $0 \cdot 1$ & $0 \cdot 5$ & $0 \cdot 1$ \\
\hline Total injuries, accidents & 45 & $3 \cdot 1$ & $18 \cdot 0$ & 43 & $2 \cdot 6$ & $10 \cdot 4$ & $0 \cdot 5$ \\
\hline Other causes & 4 & $0 \cdot 3$ & $1 \cdot 6$ & 12 & $0 \cdot 7$ & $2 \cdot 9$ & $-0 \cdot 4$ \\
\hline Impossible to specify & 11 & $0 \cdot 8$ & $4 \cdot 4$ & 17 & $1 \cdot 0$ & $4 \cdot 1$ & $-0 \cdot 2$ \\
\hline All causes & 250 & $17 \cdot 2$ & $100 \cdot 0$ & 412 & $25 \cdot 3$ & $100 \cdot 0$ & $-8 \cdot 1^{\star \star \star}$ \\
\hline
\end{tabular}

${ }^{\star} \mathrm{p}<0 \cdot 05 ;{ }^{\star \star \star} \mathrm{p}<0 \cdot 001$.

Some totals do not add up because of rounding.

of severe malnutrition by verbal autopsy and by arm circumference measurement before death $(<110 \mathrm{~mm})$ was $86 \%$. Similarly, the category of "complications of small size at birth" was not supported by anthropometry but by a statement that the newborn was unusually small at birth. This would have included babies with a short gestation and small for dates babies and probably underestimated low birth weight in this area, where half of the newborn infants weigh less than $2500 \mathrm{~g}$ (unpublished observations).

Two cause specific mortality indicators are presented: age specific rates and percentage distributions. The statistical significance of the differences between the study and comparison areas was tested by comparing incidence density rates. ${ }^{12}$ Percentage distributions were used to rank the causes of death and assess their relative importance in both areas. The findings of two years were combined in this analysis to reduce the effect of possible annual variations in causes of death.

The age categories were selected functionally: neonates are at risk of complications of low birth weight and delivery related problems, infants aged $1-5$ months of severe acute lower respiratory tract infections, and children aged 6-35 months of malnutrition and complications of measles.

\section{Results}

Among neonates complications of small size at birth were the leading cause of death, followed by neonatal tetanus, complications of birth trauma, respiratory infections, and a group of other neonatal infections (table I). Neonatal mortality in the study area was significantly lower than in the comparison area, and $90 \%$ of the difference was due to neonatal tetanus. The relative risk of dying from neonatal tetanus in the comparison area was $3 \cdot 7$ (95\% confidence interval $2 \cdot 4$ to $5 \cdot 8$ ).
Among infants aged 1 to 5 months acute lower respiratory tract infection was the leading cause of death, accounting for one third of the total (table II). Other important causes of death were severe malnutrition (usually due to lack of breastfeeding), acute watery diarrhoea, and accidents, including sudden infant deaths. The overall mortality was lower, but not significantly, in the study area than in the comparison area.

Among children aged 6 to 35 months the main causes of death were persistent diarrhoea associated with severe malnutrition, followed by acute lower respiratory infection, acute non-watery diarrhoea, and drowning (table III). Overall mortality was $30 \%$ lower in the study area, and one third of the difference was the result of a $93 \%$ lower measles related mortality: the relative risk of dying from measles or its complication in the comparison area relative to the study area was 13.9 ( $95 \%$ confidence interval 5.7 to 33.8$)$. Mortality rates associated with persistent diarrhoea and severe malnutrition and, to a lesser extent, those associated with acute lower respiratory infection were also significantly lower, with relative risks of $1 \cdot 7(1 \cdot 3$ to $2 \cdot 4)$ and $2 \cdot 1(1 \cdot 4$ to $3 \cdot 2)$ respectively.

Finally, women aged 15 to 44 years experienced a slightly lower overall mortality in the study area (table IV), with a significantly lower mortality from direct obstetric causes (relative risk 1.73 (1.02 to 2.93)), and particularly from abortion related deaths (relative risk $2 \cdot 7(1 \cdot 1$ to $6 \cdot 7))$.

\section{Discussion}

There were no known socioeconomic differences between populations in the two study areas. By applying the mortality rates of the comparison area to the population of the study area, we estimated that 60 deaths were prevented among neonates in the study area, 18 among infants aged 1-5 months, 117 among 


\begin{tabular}{|c|c|c|c|c|c|c|c|}
\hline \multirow[b]{2}{*}{ Cause of death } & \multicolumn{3}{|c|}{ Study area $(n=44317)$} & \multicolumn{3}{|c|}{ Comparison area $(n=40675)$} & \multirow{2}{*}{$\begin{array}{l}\text { Difference } \\
\text { between } \\
\text { rates }\end{array}$} \\
\hline & No & Rate & $\%$ & No & Rate & $\%$ & \\
\hline Acute watery diarrhoea & 3 & 0.7 & $2 \cdot 9$ & 4 & $1 \cdot 0$ & 3.5 & $-0 \cdot 3$ \\
\hline Acute non-watery diarrhoea & 3 & 0.7 & $2 \cdot 9$ & 2 & 0.5 & 1.7 & $0 \cdot 2$ \\
\hline Persistent diarrhoea & 6 & $1 \cdot 4$ & $5 \cdot 9$ & 4 & $1 \cdot 0$ & 3.5 & $0 \cdot 4$ \\
\hline Acute respiratory infection & 1 & $0 \cdot 2$ & $1 \cdot 0$ & 1 & $0 \cdot 2$ & 0.9 & 0.0 \\
\hline Chronic respiratory infection & 6 & 1.4 & $5 \cdot 9$ & 7 & 1.7 & $6 \cdot 1$ & $-0 \cdot 3$ \\
\hline Other infectious diseases & 16 & $3 \cdot 6$ & $15 \cdot 7$ & 18 & $4 \cdot 4$ & $15 \cdot 7$ & $-0 \cdot 8$ \\
\hline Total infectious diseases (excluding obstetric sepsis) & 35 & $7 \cdot 9$ & $34 \cdot 3$ & 36 & $8 \cdot 9$ & $31 \cdot 3$ & $-1 \cdot 0$ \\
\hline Abortion & 6 & $1 \cdot 4$ & $5 \cdot 9$ & 15 & $3 \cdot 7$ & 13.0 & $-2 \cdot 3^{\star}$ \\
\hline Postpartum sepsis & 1 & $0 \cdot 2$ & 1.0 & 2 & 0.5 & 1.7 & $-0 \cdot 3$ \\
\hline Postpartum haemorrhage & 7 & 1.6 & $6 \cdot 9$ & 4 & $1 \cdot 0$ & 3.5 & 0.6 \\
\hline Eclampsia & 4 & 0.9 & $3 \cdot 9$ & 5 & $1 \cdot 2$ & $4 \cdot 3$ & $-0 \cdot 3$ \\
\hline Obstructed labour & 1 & $0 \cdot 2$ & $1 \cdot 0$ & 2 & 0.5 & 1.7 & $-0 \cdot 3$ \\
\hline Other obstetric & 3 & $0 \cdot \overline{7}$ & $2 \cdot 9$ & 7 & $1 \cdot 7$ & $6 \cdot 1$ & $-1 \cdot 0$ \\
\hline Total obstetric causes & 22 & $5 \cdot 0$ & $21 \cdot 6$ & 35 & $8 \cdot 6$ & $30 \cdot 4$ & $-3 \cdot 6^{\star}$ \\
\hline Accidents & 7 & $1 \cdot 6$ & $6 \cdot 9$ & 5 & $1 \cdot 2$ & $4 \cdot 3$ & 0.4 \\
\hline Suicide & 10 & $2 \cdot 3$ & $9 \cdot 8$ & 7 & 1.7 & $6 \cdot 1$ & 0.6 \\
\hline Homicide & 1 & $0 \cdot 2$ & $1 \cdot 0$ & 1 & $0 \cdot 2$ & 0.9 & $0 \cdot 0$ \\
\hline Total injuries & 18 & $4 \cdot 1$ & $17 \cdot 6$ & 13 & $3 \cdot 2$ & $11 \cdot 3$ & 0.9 \\
\hline Non-infectious diseases (acute and chronic) & 9 & $2 \cdot 0$ & $8 \cdot 8$ & 14 & 3.4 & $12 \cdot 2$ & $-1 \cdot 4$ \\
\hline Other causes & 13 & 2.9 & $12 \cdot 7$ & 12 & $3 \cdot 0$ & $10 \cdot 4$ & $0 \cdot 1$ \\
\hline Impossible to specify & 5 & $1 \cdot 1$ & 4.9 & 5 & $1 \cdot 2$ & $4 \cdot 3$ & $-0 \cdot 1$ \\
\hline All causes & 102 & $23 \cdot 0$ & $100 \cdot 0$ & 115 & $28 \cdot 3$ & $100 \cdot 0$ & $-5 \cdot 3$ \\
\hline
\end{tabular}

children aged 6-35 months, and 23 among women aged 15-44 years.

Owing to the frequency of home visits and the intensive supervision of community health workers the numbers of deaths recorded as well as the denominators used to calculate mortality were likely to be accurate. Data on cause of death, however, should be interpreted with caution. In areas such as Matlab, where more than $95 \%$ of all deaths occur without medical attendance and necropsies are impossible, a carefully conducted verbal autopsy is the only alternative for assessing cause specific mortality. Some underlying causes of death, such as malnutrition, measles, or abortion, may, however, go unrecognised.

The data suggest that a few preventive components of the maternal and child health and family planning programme were effective in reducing mortality from neonatal tetanus, measles, persistent diarrhoea with severe or recent wasting, and complications of pregnancy. This impact seemed largely attributable to measles and tetanus immunisation, and, to a lesser extent, to family planning.

The effectiveness of tetanus toxoid immunisation of all women of childbearing age has already been shown in Matlab. ${ }^{1314}$ The difference in measles mortality between the two areas, although probably underestimated because of the underreporting of late measles related deaths, is consistent with the findings of other studies done in the same area. ${ }^{1516}$ These results suggest that in areas with scarce resources and weak immunisation coverage a selective programme of immunisation limited to measles and tetanus could be a practical interim strategy to achieve significant reductions in mortality.

The reason for the lower mortality associated with persistent diarrhoea and severe malnutrition observed in the study area is not as clear: the death rates associated with either "persistent diarrhoea alone" or "other severe malnutrition" were not different. The nutrition rehabilitation unit at Matlab admits mainly children referred by the community health workers from the study area, but its efficacy in preventing deaths is uncertain. The family planning programme may also have contributed to this difference by allowing a longer duration of breast feeding, which has been shown to reduce the risk of dying in severely malnourished children. ${ }^{17}$

Among women of reproductive age family planning is likely to explain both the lower abortion related death rate, a result of fewer unwanted pregnancies, and the lower direct obstetric related death rate, a result of fewer pregnancies. ${ }^{18}$

The effects of distributing oral rehydration packets and vitamin A capsules could not be determined because they were distributed in both areas.

Finally, the lower overall mortality of women and young children in the study area may have resulted from a better access to curative services and better quality care, particularly for infectious diseases. The lower mortality due to respiratory tract infections among children aged 6-35 months, for example, may have been due to easier access to antibiotics at the decentralised clinics in the study area. The small size of this differential, however, suggests that curative services in the study area were still insufficiently used. This is particularly true for women and infants, who rarely seek care outside their homes because of cultural constraints.

\section{TOWARDS A MORE BALANCED STRATEGY}

Our data suggest that in addition to preventive services provided at home, specific curative services have the potential to reduce mortality further in this area if they address the health priorities identified and if they are also delivered in the home.

Firstly, a maternity care programme that includes antenatal care, attendance at deliveries by qualified midwives, systematic postpartum home visits, and an effective referral system could reduce both maternal mortality and early neonatal mortality. Secondly, a programme for controlling acute lower respiratory infections, including case detection and appropriate antibiotic treatment by village health workers, could also reduce mortality among infants aged $1-5$ months. ${ }^{14}$ Thirdly, although the contribution of shigellosis could not be assessed in this study, another study in rural Bangladesh indicated that at least half of all cases of diarrhoea with blood were due to Shigella $\mathrm{spp} .{ }^{20} \mathrm{~A}$ community based dysentery control programme, including case detection and appropriate antibiotic 
treatment, could reduce deaths among children aged 6-35 months.

Even assuming a good individual efficacy, the impact of such interventions on infant and child mortality may be less than the sum of their isolated effects. ${ }^{2}$ Children in areas with a high mortality are exposed to many risks, concurrent and sequential. We must also be concerned with issues of equitable distribution, cost, and operational constraints. The conditions of the experiment in The Gambia, which indicated an impressive impact of curative services on infant and maternal mortality, cannot be replicated here. ${ }^{21}$ While we do not ignore the potential of socioeconomic progress and environmental changes to reduce infant and maternal mortality, we have deliberately focused on health services because they seem less difficult to implement in the short term than socioeconomic reforms.

Although our conclusions apply only to the area in which this study was done, we believe that the approach used, despite its exclusive focus on mortality, can help to define the required balance between preventive and curative interventions.

We gratefully acknowledge the contribution of: the field staff and supervisors of the Matlab Demographic Surveillance System and maternal, child health, and family planning projects, Drs $M$ Yunus, K Zaman, E Hoque, H Rahman, S Alam, S Akhter, Mrs M Alam, Mrs F Ahmed, Ms N Sultana, and Ms $Z$ Nasreen, Drs $M$ Koenig, M Strong, F Henry, A Hall, and R Eeckels.

The Matlab Demographic Surveillance System was funded by the Canadian International Development Assistance, the Matlab maternal, child health, and family planning project by the Norwegian Aid Agency, the World University Service of Canada, the Dutch government, the Ford Foundation, and the French government. A Briend was on secondment from the Institut Francais de Recherche Scientifique pour le Développement en Coopération (ORSTOM). ICDDR,B is also supported by Aga Khan Foundation, Arab Gulf Programme, Australia, Belgium, Denmark, France, Japan, Saudi Arabia, Switzerland, the United Kingdom, the United States, Unicef, United Nations Development Programme, the World Health Organisation, and the World Bank.
1 Walsh JA, Warren KS. Selective primary health care: An interim strategy for disease control in developing countries. New Engl f Med 1979;30:967-74

2 Mosley WH. Will primary health care reduce infant and child mortality? A critique of some current strategies, with special reference to Africa and Asia. In: Proceedings of the seminar on social policy, health policy and mortality prospects. Paris: International Union for the Scientific Study of Population, 1983.

3 Graham W. Measuring the mortality impact of health interventions in developing countries: Why bother? f Biosc Sci 1989;suppl 10:69-78.

4 Foster SO. Ten priorities for child health. In: Jelliffe DB, Jelliffe EFP, eds. Advances in international maternal and child health. Oxford: Clarendon Press, Advances in in $1985: 97-110$

5 Gwatkin DR, Wilcox JR, Wray J. Can health and nutrition interventions make a difference? Washington, DC: Overseas Development Council, 1980.

6 Berggren WL, Ewbank DC, Berggren GG. Reduction of mortality in rural Haiti through a primary health care program. $N$ Engl f Med 1981;304: $1324-30$

7 Ewbank DC. Uses of mortality data for evaluating the success of specific health and development programmes. In: Databases for mortality measurement. New York: United Nations, 1984

8 Ruzicka LT, Chowdhury AKMA. Demographic surveillance system-Matlab: methods and procedures. Dhaka: ICDDR,B, 1978. (Scientific Report No 9 Vol 1.)

9 Bhatia S, Mosley WH, Faruque ASG, Chakraborty J. The Matlab family planning and health services project. Stud Fam Plann 1980;11:202-12.

10 World Health Organisation. Manual of the international statistical classification of diseases, injuries and causes of death. IXth revision. Geneva: WHO, 1977.

1 Briend A, Woityniak B, Rowland MGM. Arm circumference and other factors in children at high risk of death in rural Bangladesh. Lancet factors in childrii:725-8.

12 Kleinbaum DG, Kupper LL, Morgenstern H. Epidemiological research. Belmont, Ca: Wadsworth, 1982 .

13 Rahman M, Chen LC, Chakraborty J. Tetanus toxoid: reduction of neonatal mortality by immunization of non-pregnant women and women during pregnancy in rural Bangladesh. Bull WHO 1982;60:261-7.

14 Black RE, Huber DH, Curlin GT. Reduction of neonatal tetanus by mass immunization of non-pregnant women: duration of protection provided by one or two doses of aluminium adsorbed tetanus toxoid. Bull WHO 1980;6:927-30.

15 Clemens JD, Stanton B, Chakraborty J, et al. Measles vaccination and childhood mortality in rural Bangladesh. Am $\mathcal{f}$ Epidemiol 1988;128(6): $1330-9$

16 Koenig MA, Fauveau V, Wojtyniak B. Potential reductions in infant and child mortality through immunisation programs: evidence from Matlab, Bangladesh. In: Proceedings of the XXIst international population conference. New Delhi: International Union for the Scientific Study of conference. New Delhi:

17 Briend A, Woityniak B, Rowland MGM. Breast feeding, nutritional state and child survival in Bangladesh. Br Med f 1988;296:879-82.

18 Fauveau V, Koenig MA, Woityniak B, Chakraborty J. The impact of a family planning and health services programme on adult female mortality. Health Policy and Planning 1988;3:271-9.

9 World Health Organisation. Clinical management of acute respiratory infections in children: a WHO memorandum. Bull WHO 1981;59:707-16.

20 Ronsmans C, Bennish ML, Wierzba T. Diagnosis and management of dysentery by Community Health Workers. Lancet 1988;ii:552-5.

21 Lamb WH, Ford FA, Lamb CMB, Whitehead RG. Changes in maternal and child mortality rates in three isolated Gambian villages over ten years. Lancet 1984;ii:912-4.

(Accepted 20 March 1990)

\section{Letter from Bombay}

\section{On editing a book in India}

\section{Sunil K Pandya}

As one of the two historians to the Neurological Society of India-hereafter referred to as the society-I had accepted, in 1987, the task of producing a volume containing analytical essays on Indian contributions to the neurosciences. This was to be published in time for the three world congresses (neurosurgery, epilepsy, and neurology) in New Delhi in 1989. I knew that this was a unique learning experience. I had underestimated just how much I would learn.

With the unanimous backing of the society and in consultation with senior neuroscientists throughout the country potential authors were identified. My first letter to each of them outlined the entire project and described the essay we wished him or her to write over the next 12 months. We provided detailed guidelines and offered all possible help. As advised by one of them each author was provided with the entire table of contents and the names and addresses of other authors so that they could discuss between themselves how best to cover the entire range of subjects without overlap and duplication. Two of those approached initially declined to write on account of heavy schedules but reconsidered their decisions on request and eventually provided excellent texts. Three of those who had readily promised to help renegued despite several reminders. One gave up as a key collaborator would not cooperate.

\section{Lackadaisical response}

Just four of the 33 authors needed help in the form of xerox prints of texts not available to them locally. All 33 carried out exhaustive searches of the literature and most sent out detailed questionnaires to their peers throughout the country. It is a sad fact that the responses to these queries were lackadaisical. "In spite of my personal requests and a subsequent general circular to all heads of departments of [the subject] at various centres, only two persons have, so far, sent information and even this is scanty. Unless I get
Bombay 400 012, Indi

Sunil K Pandya, Ms, neurosurgeon

BrMed f 1990;301:107-8 